[Agr. Biol. Chem., Vol. 29, No. 11, p. 1009 1015, 1965]

\title{
Studies on Utilization of Hydrocarbons by Yeasts
}

\author{
Part II. Diterminal Oxidation of Alkanes by Yeasts \\ By Shigeo Ogino, ${ }^{*}$ Keiji Yano, Gakuzo Tamura \\ and Kei Arima
}

Department of Agricultural Chemistry, Faculty of

Agriculture, The University of Tokyo

Received June 8, 1965

\begin{abstract}
We found that the yeast $\mathrm{Y}-3$ strain reported in the previous paper ${ }^{1 /}$ has a diterminal oxidation system of hydrocarbon.

This yeast capable of growing in mineral-salts solution with hydrocarbons as sole source of carbon produced a series of dioic acid from $n$-undecane. These acids are 1,11 undecane dioic acid, 1,9-nonane dioic acid (azelaic acid), 1,7-heptane dioic acid (pimelic acid) and 1,5-pentane dioic acid (glutaric acid). 1,10-Decane dioic acid (sebacic acid) was also isolated from $n$-decane cultures.

Azelaic acid was partially transformed into pimelic acid and glutaric acid by treating it with resting cells of this yeast.

1,11-Undecane dioic was also transformed into azelaic acid pimelic acid, and glutaric acid by the same treatment as described above.
\end{abstract}

Microbial oxidation of aliphatic hydrocabon is believed to occur by a monoterminal oxidation. . $^{2-51}$

Recently, A. S. Kester and J. W. Foster ${ }^{6 !}$ showed that hydrocarbons were oxidized by a diterminal oxidation mechanism in corynebacterial organisms besides a monoterminal mechanism.

The present paper deals with diterminal oxidation of hydrocarbons by the yeast $\mathrm{Y}-3$ strain.

\section{MATERIASL AND METHODS}

\section{Organism and culture methods}

All the experiments were performed with the yeast,

* Present address; Research Department, Pharmaceutical division of Sumitomo Chemical Co., Ltd. Kasugade-cho, Konohana-ku Osaka.

1) K. Arima, S. Ogino, K. Yano and G. Tamura, This Journal, 29, 1004 (1965).

2) J. E. Stewart, R. E. Kallio, D. P. Stevenson, A.C. Jones and D. O Schissler, J. Bacteriol., 78, 441 (1959).

3) E. R. Leadbetter and J. W. Foster, Nature, 184, 1428.

4) M. H. Proctor, Biochim. Biophys. Acta, 42, 559 (1960).

5) M. T. Heydeman, ibid., 42, 557 (1960).

6) A, S. Kester and J. W. Foster, J. Bacteriol., 85, 859 (1963).
Y-3 strain, tentatively assigned to Pichia sp. in the previous paper. ${ }^{1\}}$

The composition of mineral salts solution used in this work was disodium phosphate $12 \mathrm{aq} .2 .5 \mathrm{~g}$, monopotassium phosphate $3.5 \mathrm{~g}$, magnesium sulfate $7 \mathrm{aq} .1 .0 \mathrm{~g}$, sodium chloride $0.5 \mathrm{~g}$, urea $0.85 \mathrm{~g}$, corn steep liquor $0.1 \mathrm{ml}$ and tap water 11 .

The hydrocarbons used were $n$-undecane of $95 \%$ purity and $n$-decane of $98 \%$ purity (Tokyo Chemical Industry Co., Ltd.)

Production of various acids in amounts suitable for isolation was carried out in 51 shaker flask containing $1.5 \mathrm{l}$ of mineral salts solution and $37.5 \mathrm{~g}$ of individual hydrocarbon as the sole source of carbon, so the $\mathrm{C} / \mathrm{N}$ ratio was 30 .

From two to five flasks were employed in each experiment. The mineral salts solution was sterilized for $15 \mathrm{~min}$. at $120^{\circ} \mathrm{C}$, and hydrocarbon was added just before inoculation. The flasks were shaken on the rotary shaker at $30^{\circ} \mathrm{C}$.

\section{Extraction of acids}

The kieselguhr was added to the broth and filtered under reduced pressure. The filtrate was acidified to $\mathrm{pH} 2.0$ with $\mathrm{H}_{2} \mathrm{SO}_{4}$ and extracted two to three 
times in a separatory funnel with equivalent volumes of ether.

The combined ether extracts were shaken with $0.5 \mathrm{~N}-\mathrm{NaOH}$ and separated in a funnel. The ether layer was washed by shaking with distilled water. The alkaline solution and washed liquor were combined and, after the acidification, were extracted with ether again.

The ether layer was dried by anhydrous sodium sulfate.

The dried ether extract was concentrated to dryness and crude acid was obtained at the yield of 30 $\mathrm{mg} / \mathrm{l}$. broth.

\section{Thin-layer chromatography}

For time course of acid formation $50 \mathrm{ml}$ of broth were taken out at intervals of adequate time and extracted as described above. The crude acids mixtures were dissolved into $0.5 \mathrm{ml}$ of ethanol. Twenty $\mu l$ of ethanolic acids solution were spotted on kieselgel $\mathrm{G}$ plate.

Two different solvent systems were used, in the ascending technique; solvent $A$, benzene-dioxane-acetic acid $(90: 25: 4)$, solvent $B$, benzene-ether-acetic acid $(9: 2: 1)$.

The plate was dried in an oven at $105^{\circ} \mathrm{C}$ for $1 \mathrm{hr}$, and acid spots were developed by spraying with bromocresol green indicator solution.

\section{Partition column chromatography}

For the isolation of various acids, partition column chromatographic technique was used. Crude acids mixtures obtained as described above were dissolved in chloroform and adsorbed on silicic acid column.

Elution was carried out by chloroform followed by chloroform-ethanol mixtures (97\% chloroform).

Dioic acids were eluted in the order of chain length.

Crude acids were recrystallized from chloroform and $n$-hexane mixtures.

\section{Gas chromatography}

Gas-liquid chromatography was carried out as following conditions.

chromatograph

Shimadzu Model GC-1B

column dimension

solid support

stationary phase

temperature

carrier gas

detector
$150 \times 0.4 \mathrm{~cm}$

chromosorb W (60/80 mesh)

DEGS- $\mathrm{H}_{3} \mathrm{PO}_{4}(1-1)$

$196^{\circ} \mathrm{C}$

nitrogen at $30 \mathrm{ml} / \mathrm{min}$

flame ionization detector type HFD-1

\section{Chemical method}

Identification of each pure acid was made by cochromatography on thin-layer, by molecular weight determination (Rast or titration), by elementary analysis and by comparison of the infrared absoption spectrum of the isolated acid with that of an authentic compound.

The mixture of acids was identified by thin-layer chromatography and gas chromatography.

Azelaic acid, pimelic acid, glutaric acid and sebacic acid were obtained from Tokyo Chemical Industry Co., Ltd.

1,11-Undecane dioic acid was synthesized by Willgerodt reaction.?)

\section{Procedures of resting cell experiments}

Yeast cells were collected at the log phase by centrifugation.

Cells were washed four times with the mineral salts solution without the nitrogen source and were suspended in the same salts solution.

The reaction mixtures were prepared as follows: to a Monod test tube were added $7 \mathrm{ml}$ of mineral salts solution with no nitrogen source, $1 \mathrm{ml}$ of $0.0 \mathrm{I} \mathrm{M}$-dioic acid solution (neutralized to $\mathrm{pH} 7.0$ by $1 \mathrm{~N}-\mathrm{NaOH}$ ) and $2 \mathrm{ml}$ of cell suspension, the cell concentration of which was five times as much as the concentration in broth at maximum growth in optical density.

The mixtures were incubated overnight at $30^{\circ} \mathrm{C}$ on Monod shaker

\section{RESULTS}

\section{Acid formation}

Acid production during growth of $Y-3$ strain on $n$-undecane was tested. The results are shown in Fig. 1.

This shows that about five spots are developed, and that the acid which appears at early stage and has the largest $R_{F}$ value disappears at $140 \mathrm{hr}$ cultivation.

The amounts of the two acids which begin to appear at $30 \mathrm{hr}$ after inoculation are gradually increasing with the passage of cultivation time.

These three acids were isolated from $n$ undecane culture and identified. But the

7) D. B. Pattison and M. Carmack, J. Am. Chem. Soc., 68, $2034(1946)$ 


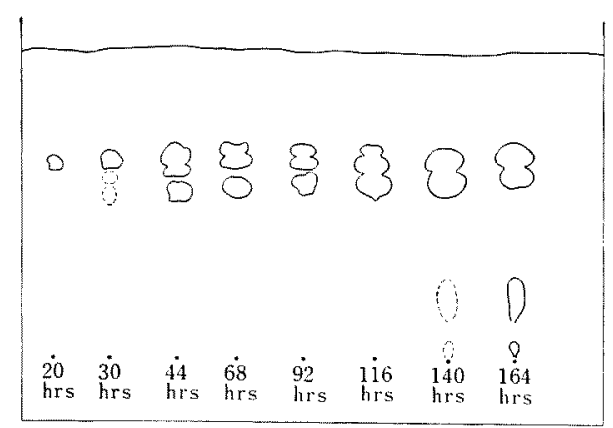

FIG. 1. Chromatogram of Organic Acids Produced by $\mathrm{Y}-3$ Strain.

Solvent benzene/dioxane/acetic acid $=90 / 25 / 4$

other two acids which began to appear at $140 \mathrm{hr}$ cultivation were not isolated.

\section{Identification of acids}

Chemical properties of organic acids obtained from $n$-undecane and n-decane cultures are shown in Table I.

These acids were isolated by column chromatography and recrystallized from adequate solvents.

The acid which had largest $R_{F}$ value agreeed with 1,11-undecane dioic acid synthesized by Willgerodt reaction by cochromatography of thin-layer.

The second acid agreed with azelaic acid and the third also agreed with pimelic acid by the same method.

The acid isolated from $n$-decane also agreed with sebacic acid. IR-spectra of these acids are shown in Fig. 2.

This shows that the acids isolated from $n$ undecane culture are 1,11-undecane dioic acid, azelaic acid and pimelic acid, respectively.

The acid isolated from $n$-decane culture is the same as sebacic acid.

Degradation of 1,11-undecane dioic acid and azelaic acid by resting cells of $Y-3$ strain

The acids obtained from resting cell incubation mixture were extracted as described above.

Identification of the extracts was carried out by thin-layer chromatography and gas chromatography.

In thin-layer chromatography two solvent systems were used.

The results are shown in Fig. 3 and 4. This shows that 1,11-undecane dioic acid is transformed into azelaic acid, pimelic acid and glutaric acid, and that azelaic acid is changed into pimelic acid and glutaric acid.

These results are supported by gas chromatography as shown in Fig. 5 and 6.

\section{DISCUSSION}

The experiments reported here show that hydrocarbon is oxidized by a diterminal oxidation mechanism in yeast.

Table I. Chemical Properties of Organic Acids ProducEd BY Y-3 STRAIN

Sample
$\begin{aligned} & \text { 1,11-Undecane dioic acid } \\ & 111.0 \sim 111.5\end{aligned}$




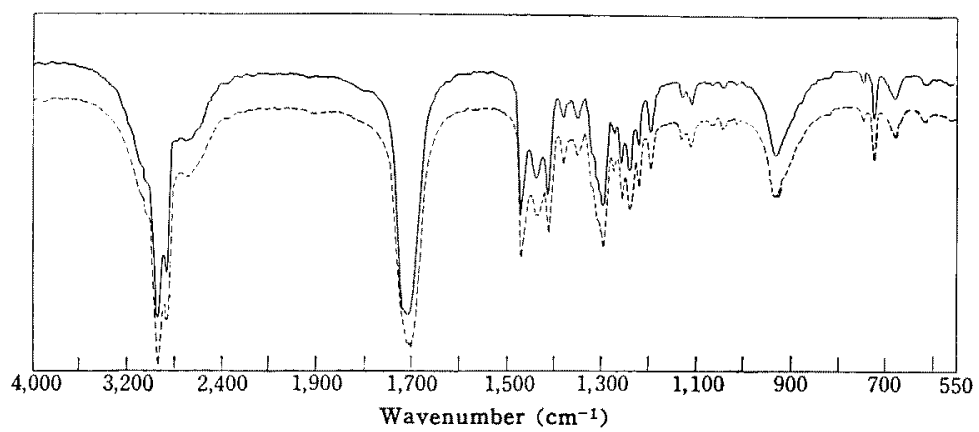

FIG. 2a. Infrared Spectrum of Acid Produced from n-Undecane by Y-3 Strain. Solid line: authentic 1,11-undecane dioic acid Broken line: microbial product

(nujol)

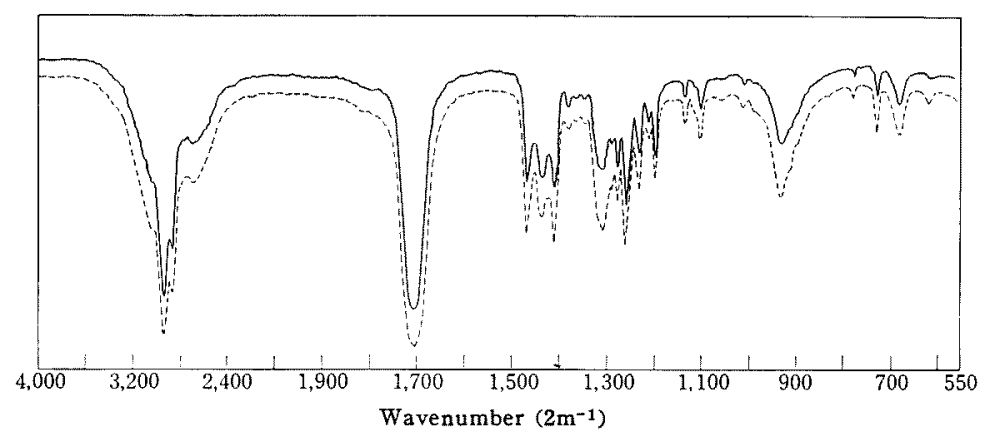

FIG. 2b. Infrared Spectrum of Acid Produced from $n$-Undecane by Y-3 Strain.

Solid line: authentic azelaic acid Broken line: microbial product

(nujol)

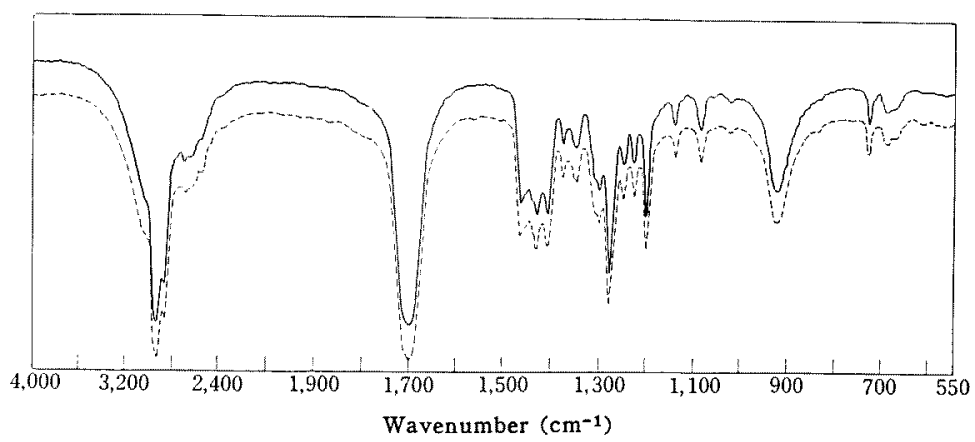

FIG. 2c. Infrared Spectrum of Acid Produced from n-Uudecane by Y-3 Strain. Solid line: authentic pimelic acid Broken line: microbial product (nujol) 


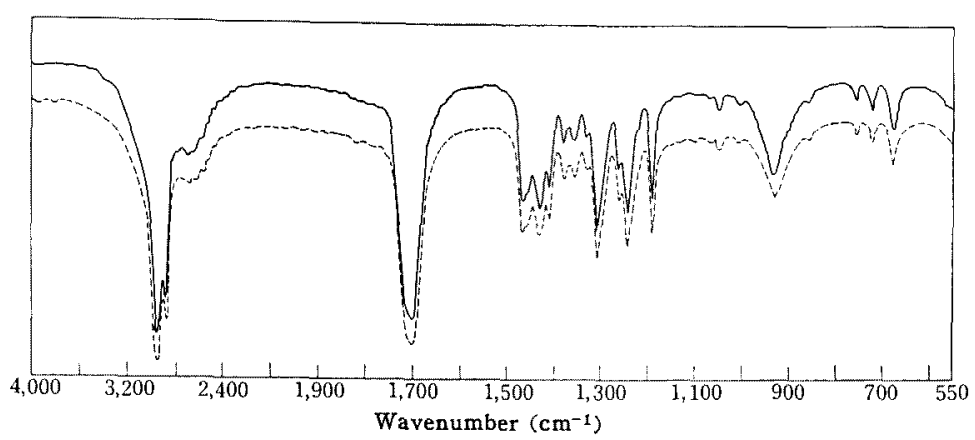

FIG. 2d. Infrared Spectrum of Acid Produced from $n$-Decane by Y-3 Strain. Solid line: authentic sebacic acid Broken line: microbial product (nujol)

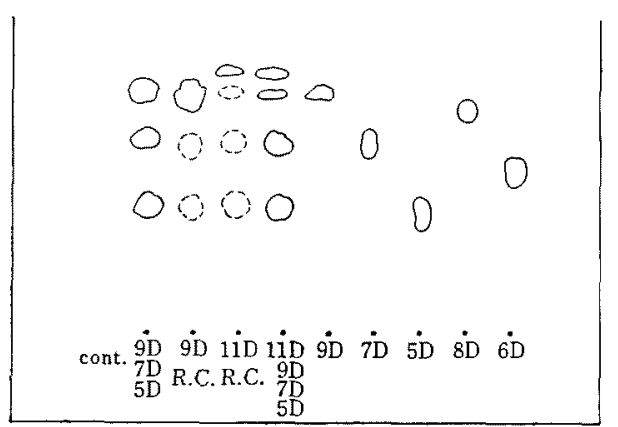

FIG. 3. Thin-layer Chromatogram from Resting Cell Experiments.

Solvent: benzene-dioxane-acetic acid $(90: 25: 4)$

Cont.: no substrate $11 \mathrm{D}: 1,11$-undecane dioic acid 9D: azelaic acid $8 \mathrm{D}$; suberic acid

7D: pimelic acid 6D: Adipic acid 5D glutaric acid R. C.: treated with resting cells.

The dioic acids produced by this yeast are metabolized by the resting cells in such a way as other dioic acids the carbon skeletons of which are shorter by two atoms than that of the substrate, are produced.

We believe that this degradation is probably carried out by $\beta$-oxidation mechanism.

In bacteria, Kester and Foster ${ }^{6}$ obtained decane and dodecane dioic acids etc., but shorter chain-length dioic acids than the substrate alkanes of their series were not demonstrated.

We could isolate azelaic and pimelic acid

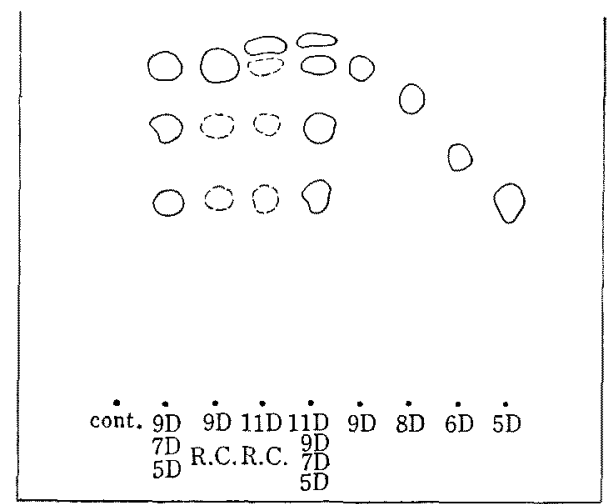

EIG. 4. Thin-layer Chromatogram from Resting Cell Experiments.

Solvent: benzene-ether-acetic acid $(9: 2: 1)$

Cont.: no substrate 11D: 1,11-Undecane dioic acid 9D: azelaic acid, $8 \mathrm{D}:$ suberic acid 7D: pimelic acid, 6D: adipic acid 5D: glutaric acid R.C.: treated with resting cells.

from $n$-undecane culture besides 1,11-undecane dioic acid.

Dioic acids pathway reported here has not yet been demonstrated hitherto in yeast.

These observations show that diterminal oxidation of alkanes may be widely distributed in microorganisms.

We could not isolate the monoic acids such as undecanoic acid, decanoic acid and nonanoic acid etc. from either cultural filtrate or cells. 


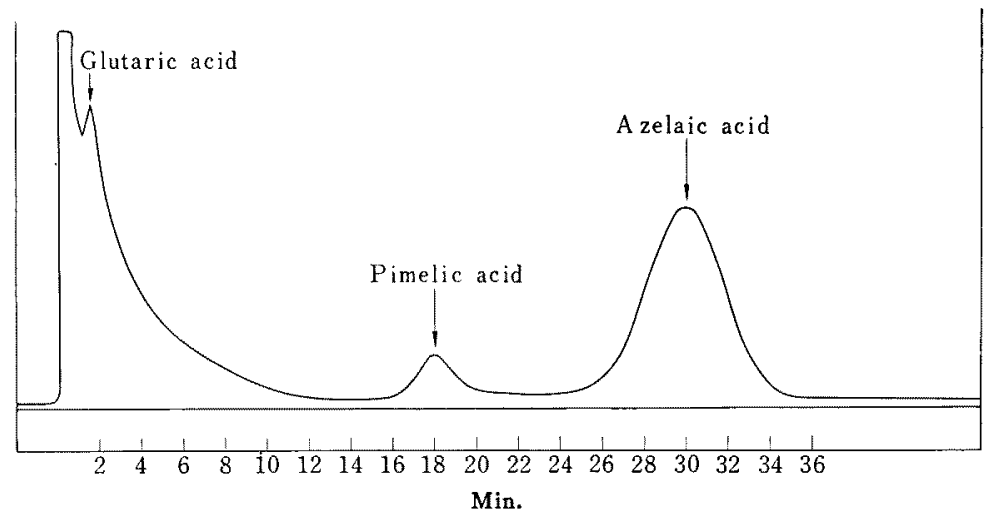

FIG. 5. Gas Chromatogram of Acids Extracted from Incubation Mixtures. Azelaic acid was treated with resting cells.

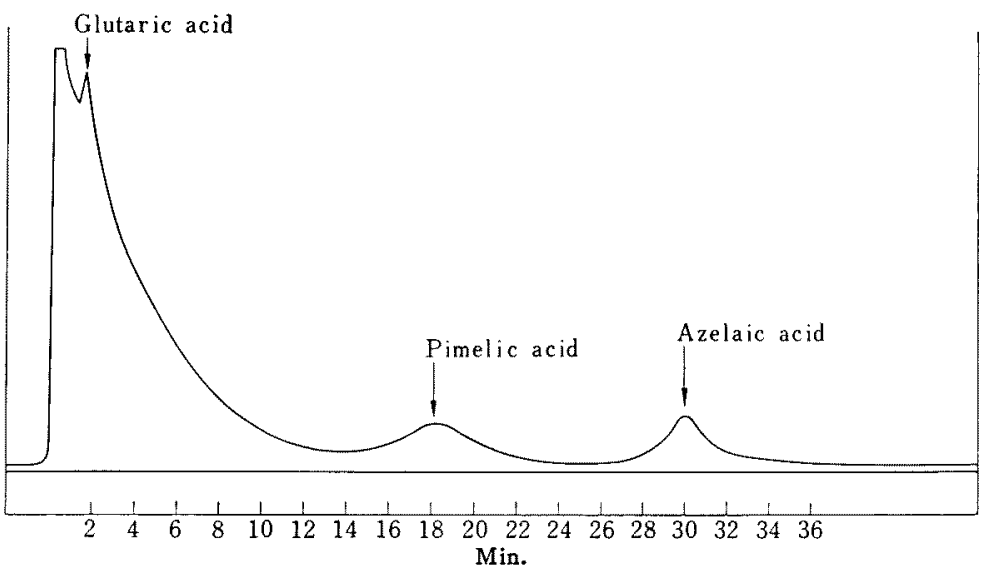

FIG. 6. Gas chromatograms of Acids Extracted from Incubation Mixtures. 1,11 -undecane dioic acid was treated with resting cells.

This may merely mean that these acids do not accumulate in detectable amounts.

After hydrolysis of extracts from cells, the acid mixtures, the carbon-chain length of which was longer than $\mathrm{C}_{13}$, were isolated.

Anyhow, there may be a monoic acid path- Fig. 7. way, although we could not isolate them.

There are at least two kinds of degradation pathway of alkanes in microorganisms: monoic acid pathway and dioic acid pathway. The scheme of these pathways is shown in 


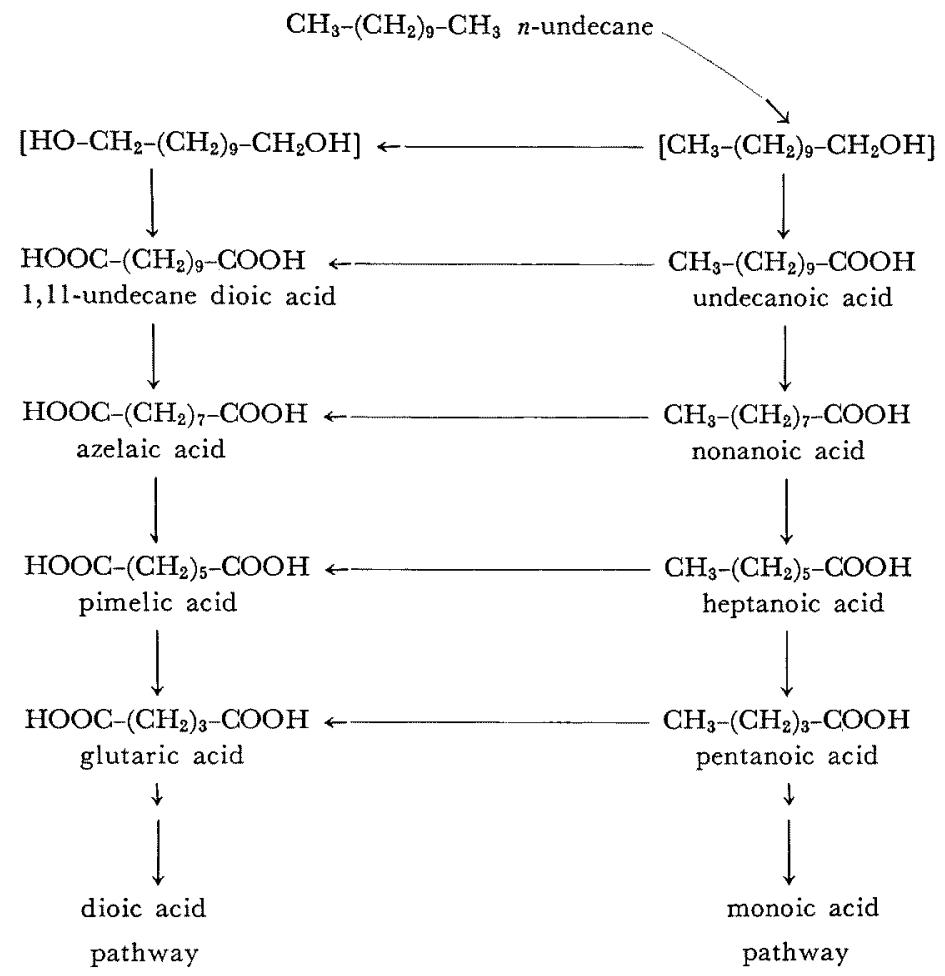

FIG. 7. Scheme of Degradation Pathway. 